\title{
End-on cyanate or end-to-end thiocyanate bridged dinuclear copper(II) complexes with a tridentate Schiff base blocking ligand: Synthesis, structure and magnetic studies
}

DOI:

10.1039/C7NJ03990E

\section{Document Version}

Accepted author manuscript

Link to publication record in Manchester Research Explorer

\section{Citation for published version (APA):}

Khan, S., Sproules, S., Natrajan, L., Harms, K., \& Chattopadhyaya, S. (2018). End-on cyanate or end-to-end thiocyanate bridged dinuclear copper(II) complexes with a tridentate Schiff base blocking ligand: Synthesis, structure and magnetic studies. New Journal of Chemistry. https://doi.org/10.1039/C7NJ03990E

\section{Published in:}

New Journal of Chemistry

\section{Citing this paper}

Please note that where the full-text provided on Manchester Research Explorer is the Author Accepted Manuscript or Proof version this may differ from the final Published version. If citing, it is advised that you check and use the publisher's definitive version.

\section{General rights}

Copyright and moral rights for the publications made accessible in the Research Explorer are retained by the authors and/or other copyright owners and it is a condition of accessing publications that users recognise and abide by the legal requirements associated with these rights.

\section{Takedown policy}

If you believe that this document breaches copyright please refer to the University of Manchester's Takedown Procedures [http://man.ac.uk/04Y6Bo] or contact uml.scholarlycommunications@manchester.ac.uk providing relevant details, so we can investigate your claim.

\section{OPEN ACCESS}



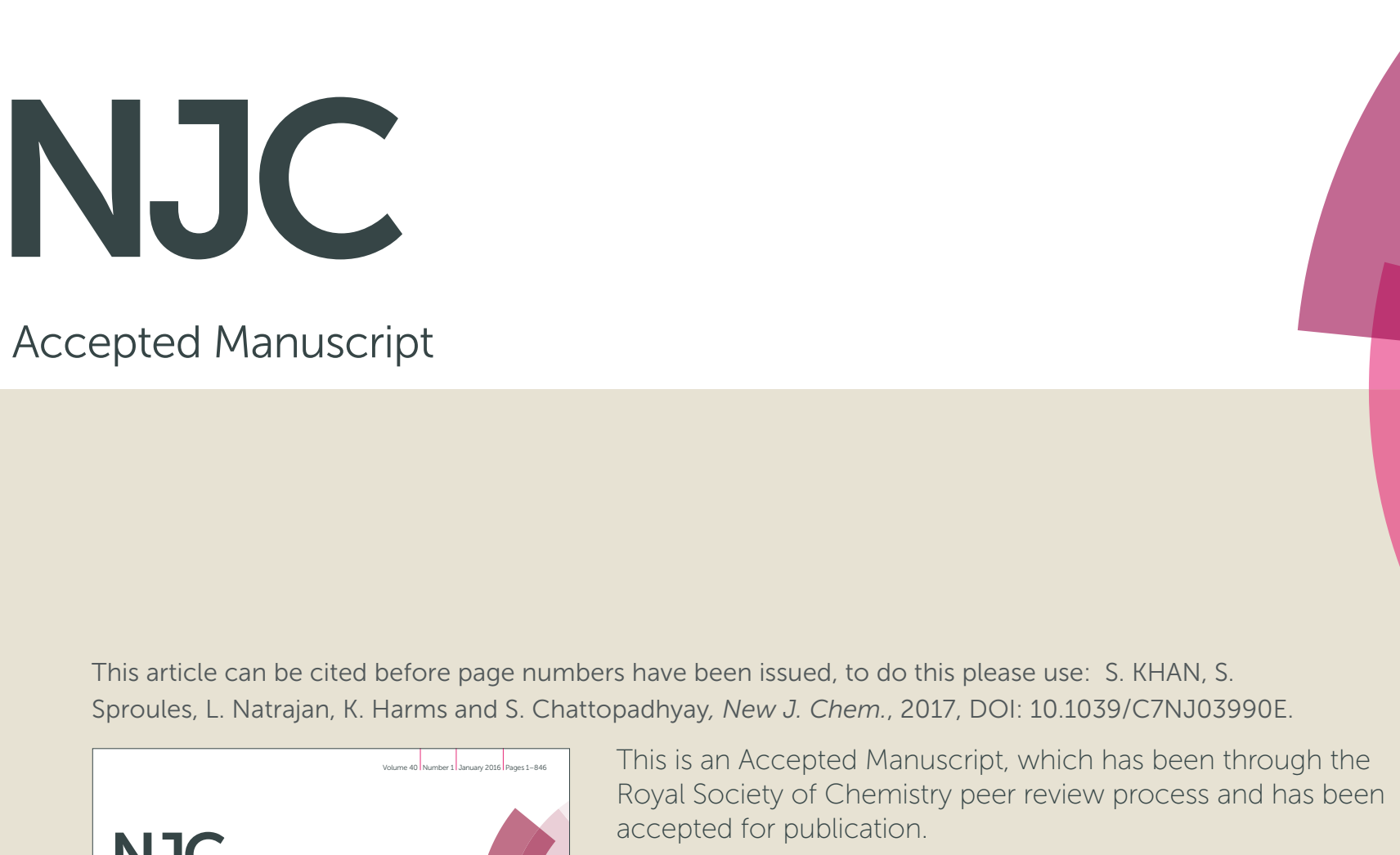

\section{Accepted Manuscript}

This article can be cited before page numbers have been issued, to do this please use: S. KHAN, S.

Sproules, L. Natrajan, K. Harms and S. Chattopadhyay, New J. Chem., 2017, DOI: 10.1039/C7NJ03990E.

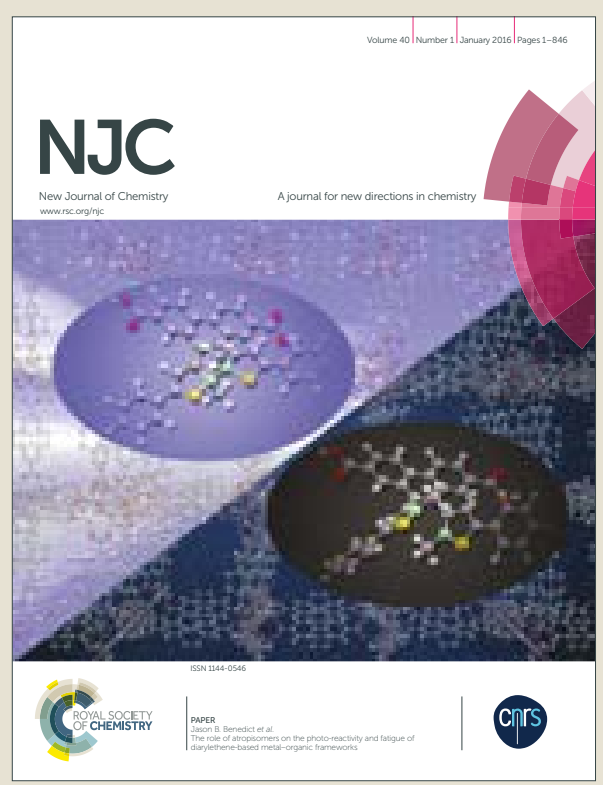

This is an Accepted Manuscript, which has been through the Royal Society of Chemistry peer review process and has been accepted for publication.

Accepted Manuscripts are published online shortly after acceptance, before technical editing, formatting and proof reading. Using this free service, authors can make their results available to the community, in citable form, before we publish the edited article. We will replace this Accepted Manuscript with the edited and formatted Advance Article as soon as it is available.

You can find more information about Accepted Manuscripts in the author guidelines.

Please note that technical editing may introduce minor changes to the text and/or graphics, which may alter content. The journal's standard Terms \& Conditions and the ethical guidelines, outlined in our author and reviewer resource centre, still apply. In no event shall the Royal Society of Chemistry be held responsible for any errors or omissions in this Accepted Manuscript or any consequences arising from the use of any information it contains. 


\title{
End-on cyanate or end-to-end thiocyanate bridged dinuclear
}

\section{copper(II) complexes with a tridentate Schiff base blocking ligand:}

\section{Synthesis, structure and magnetic studies}

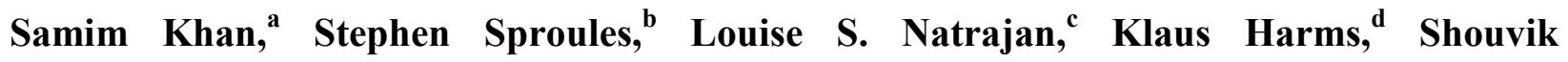 \\ Chattopadhyay ${ }^{\mathrm{a}, *}$ \\ ${ }^{a}$ Department of Chemistry, Inorganic Section, Jadavpur University, Kolkata - 700 032, India. \\ ${ }^{b}$ WestCHEM, School of Chemistry, University of Glasgow, Glasgow G12 8QQ, United Kingdom. \\ ${ }^{c}$ School of Chemistry, The University of Manchester, Oxford Road, Manchester M13 9PL, United \\ Kingdom. \\ ${ }^{d}$ Fachbereich Chemie, Philipps-Universität Marburg, Hans-Meerwein-Straße, D-35032 \\ Marburg, Germany.
}

\begin{abstract}
Two dinuclear copper(II) complexes, $\left[\mathrm{Cu}_{2}(L)_{2}\left(\mu_{1,1}-\mathrm{NCO}\right)_{2}\right]$ (1) and $\left[\mathrm{Cu}(\mathrm{L})_{2}\left(\mu_{1,3^{-}}\right.\right.$ $\left.N C S)_{2}\right] \cdot \mathrm{H}_{2} \mathrm{O} \cdot \mathrm{DMF}$ (2) have been synthesized using a tridentate $\mathrm{N}_{2} \mathrm{O}$ donor Schiff base ligand (HL) [1((2-(ethylamino)ethylimino)methyl)naphthalen-2-ol] and characterized by elemental analysis, spectral study and X-ray crystallography. Both complexes are centrosymmetric dimers in which square pyramidal copper(II) centres are connected by pseudo-halides; end-on cyanate in $\mathbf{1}$ and end-to-end (EE) thiocyanate in $\mathbf{2}$. Variable temperature (2-300 K) magnetic susceptibility measurements indicate the presence of ferromagnetic exchange coupling between copper(II) centres in complex $\mathbf{1}\left(J=0.97 \mathrm{~cm}^{-1}\right)$, and antiferromagnetic exchange coupling in $\mathbf{2}(J=-0.6$ $\left.\mathrm{cm}^{-1}\right)$.
\end{abstract}

Keywords: Copper(II), Schiff base; Crystal structures, Magnetic properties 


\section{Introduction}

Designed synthesis of di and polynuclear copper(II) complexes is an interesting area of research for their diverse structures and potential applications in magnetic materials. ${ }^{1}$ Although different bridging ligands have been employed for their synthesis, use of pseudohalide as bridging ligand in preparing such complexes is a common practice, as pseudohalides with various bridging modes can lead to the formation of complexes with surprising difference in the structures and magnetic properties. ${ }^{2}$ The most widely used pseudo-halide is azide, ${ }^{3}$ and the chemistry of azide coordinated complexes have already been reviewed. ${ }^{4}$ On the other hand, although works on cyanato and thiocyanato bridged complexes are relatively less, reports on the synthesis and characterization of such complexes could also be found in literature. ${ }^{5}$ The structures of cyanate and thiocyanate are very similar with both having linearly exposed $\mathrm{N} \cdots \mathrm{C} \cdots \mathrm{X}(\mathrm{X}=\mathrm{O}$ in cyanate and $\mathrm{X}=\mathrm{S}$ in thiocyanate) skeleton. Both these ligands may be used as terminal ligands ${ }^{6}$ and may be used as bridging ligands. ${ }^{7}$ They may show end-on (EO) and/or endto-end (EE) binding modes when act as bridging ligands. ${ }^{8}$

Focusing to copper(II), both type of bridges can be either symmetrical or unsymmetrical due to active Jahn-Teller effects on the metal centre which make the structures even more versatile. $^{9}$ The magnetic exchange via the pseudo-halide bridge can be ferro- or antiferromagnetic. When pseudo-halide ligand bridges two copper(II) centres in an end-on, basal-basal manner, ferromagnetic exchange coupling is observed only when the value of $\mathrm{Cu}-$ $\mathrm{N}-\mathrm{Cu}$ angle is less than $109^{\circ}$, whereas antiferromagnetic exchange coupling is observed when the value of $\mathrm{Cu}-\mathrm{N}-\mathrm{Cu}$ angle is $109^{\circ} .{ }^{10}$ On the other hand, any meaningful overlap between magnetic orbitals is absent for end-on basal-apical bridges leading to very small magnetic couplings. ${ }^{11}$ Same is the case for the end-to-end pseudo-halide bridged complexes due to 
relatively longer distance between the copper(II) centres. ${ }^{12}$ In the present work, a tridentate Schiff base, 1((2-(ethylamino)ethylimino)methyl)naphthalen-2-ol, (HL) has been used to prepare two copper(II) complexes in presence of cyanate and thiocynate coligands. It has been observed that cyanate forms EO bridges and thiocyanate forms EE bridges to form two centrosymmetric dinuclear complexes, $\quad\left[C u_{2}(L)_{2}\left(\mu_{1,1}-N C O\right)_{2}\right] \quad(\mathbf{1}) \quad$ and $\quad\left[C u_{2}(L)_{2}\left(\mu_{1,3}-N C S\right)_{2}\right] \cdot H_{2} O \cdot D M F$ respectively. Variable temperature magnetic susceptibility was measured. EE thiocyanate transmits antiferromagnetic interactions, whereas EO cyanate transmits ferromagnetic interactions among copper(II) centres in $\mathbf{1}$ and $\mathbf{2}$ respectively.

\section{Preparations}

Preparation of $\left[\mathrm{Cu}_{2}(L)_{2}\left(\mu_{1,1}-\mathrm{NCO}\right)_{2}\right]$ (1)

The Schiff base ligand, HL, was prepared by the condensation of N-ethyl-1,2diaminoethane $(0.105 \mathrm{~mL}, 1 \mathrm{mmol}, 0.837 \mathrm{~g} / \mathrm{mL})$ and 2-hydroxy-1-acetonaphthone (186 mg, 1 mmol) in methanol solution under reflux for ca. $1 \mathrm{~h}$. The Schiff base ligand was not isolated. A methanol (10 mL) solution of copper(II) acetate monohydrate (200 mg, $1 \mathrm{mmol})$ was added into the methanol solution of the ligand followed by addition of methanol-water solution of sodium cyanate $(65 \mathrm{mg}, 1 \mathrm{mmol})$ with constant stirring. The stirring was continued for an additional ca. 2 h. Dark green single crystals, suitable for X-ray diffraction, were obtained after few days by slow evaporation of dark green acetonitrile solution of the compound in open atmosphere.

Yield: $267 \mathrm{mg}$ [73.98\%, based on copper (II)]; Anal. Calc. for $\mathrm{C}_{34} \mathrm{H}_{38} \mathrm{Cu}_{2} \mathrm{~N}_{6} \mathrm{O}_{4}$ (721.78): C, 56.58; H, 5.31; N, 11.64\%. Found: C, 56.5; H, 5.4; N, 11.4\%. ESI-MS (positive ion mode, acetonitrile) m/z: $678.24\left[\left\{\mathrm{Cu}_{2}(\mathrm{~L})_{2}\left(\mu_{1,1}-\mathrm{NCO}\right)\right\}\right]^{+} ; 318[\mathrm{Cu}(\mathrm{L})]^{+}$. FT-IR $\left(\mathrm{KBr}, \mathrm{cm}^{-1}\right): 3201\left(v_{\mathrm{NH}}\right)$, 
$2215\left(v_{\mathrm{NCO}}\right), 1615\left(v_{\mathrm{C}=\mathrm{N}}\right) ; \mathrm{UV}-\mathrm{Vis}, \lambda_{\max }(\mathrm{nm})\left[\varepsilon_{\max }\left(\mathrm{Lmol}^{-1} \mathrm{~cm}^{-1}\right)\right]($ acetonitrile $): 310\left(1.3 \times 10^{4}\right)$, $387\left(1.25 \times 10^{4}\right), 595\left(2.61 \times 10^{2}\right)$.

Preparation of $\left[\mathrm{Cu}_{2}(\mathrm{~L})_{2}\left(\mu_{1,3}-\mathrm{NCS}\right)_{2}\right] \cdot \mathrm{DMF} \cdot \mathrm{H}_{2} \mathrm{O}$ (2)

It was prepared in a similar method as that of complex 1, except that sodium thiocyanate (81 mg, $1 \mathrm{mmol}$ ) was used instead of sodium cyanate. Single crystals, suitable for X-ray diffraction, were obtained after few days on slow evaporation of the solution.

Yield: $318 \mathrm{mg}\left[\sim 67.9 \%\right.$, based on copper (II)]; Anal. Calc. for $\mathrm{C}_{40} \mathrm{H}_{56} \mathrm{Cu}_{2} \mathrm{~N}_{8} \mathrm{O}_{6} \mathrm{~S}_{2}$ (936.12): C, 51.32; H, 6.03; N, 11.97\%. Found: C, 51.2; H, 6.1; N, 11.8\%. ESI-MS (positive ion mode, acetonitrile) m/z: $696.07\left[\left\{\mathrm{Cu}_{2}(\mathrm{~L})_{2}\left(\mu_{1,3}-\mathrm{NCS}\right)\right\}\right]^{+} ; 318[\mathrm{Cu}(\mathrm{L})]^{+}$. FT-IR $\left(\mathrm{KBr}, \mathrm{cm}^{-1}\right): 3227$ $\left(v_{\mathrm{NH}}\right), 2101\left(v_{\mathrm{NCS}}\right), 1601\left(v_{\mathrm{C}=\mathrm{N}}\right)$; UV-Vis, $\lambda_{\max }(\mathrm{nm})\left[\varepsilon_{\max }\left(\mathrm{Lmol}^{-1} \mathrm{~cm}^{-1}\right)\right]$ (acetonitrile): 312 $\left(1.45 \times 10^{4}\right), 388\left(1.21 \times 10^{4}\right), 594\left(2.25 \times 10^{2}\right)$.

\section{Result and discussion}

\section{Synthesis}

The tridentate $\mathrm{N}_{2} \mathrm{O}$ donor Schiff base ligand (HL) was produced by the condensation of N-ethyl-1,2-diaminoethane and 2-hydroxy-1-acetonaphthone following the literature method. ${ }^{\text {a }}$ The monocondensed Schiff base ligand, HL, on reaction with copper(II) acetate monohydrate and different pseudo-halides gave copper(II) complexes, $\left[\mathrm{Cu}_{2}(\mathrm{~L})_{2}\left(\mu_{1,1}-\mathrm{NCO}\right)_{2}\right]$ (1) and $\left[\mathrm{Cu}_{2}(\mathrm{~L})_{2}\left(\mu_{1,3}-\mathrm{NCS}\right)_{2}\right] \cdot(\mathrm{DMF}) \cdot \mathrm{H}_{2} \mathrm{O}(\mathbf{2})($ Scheme 1). 


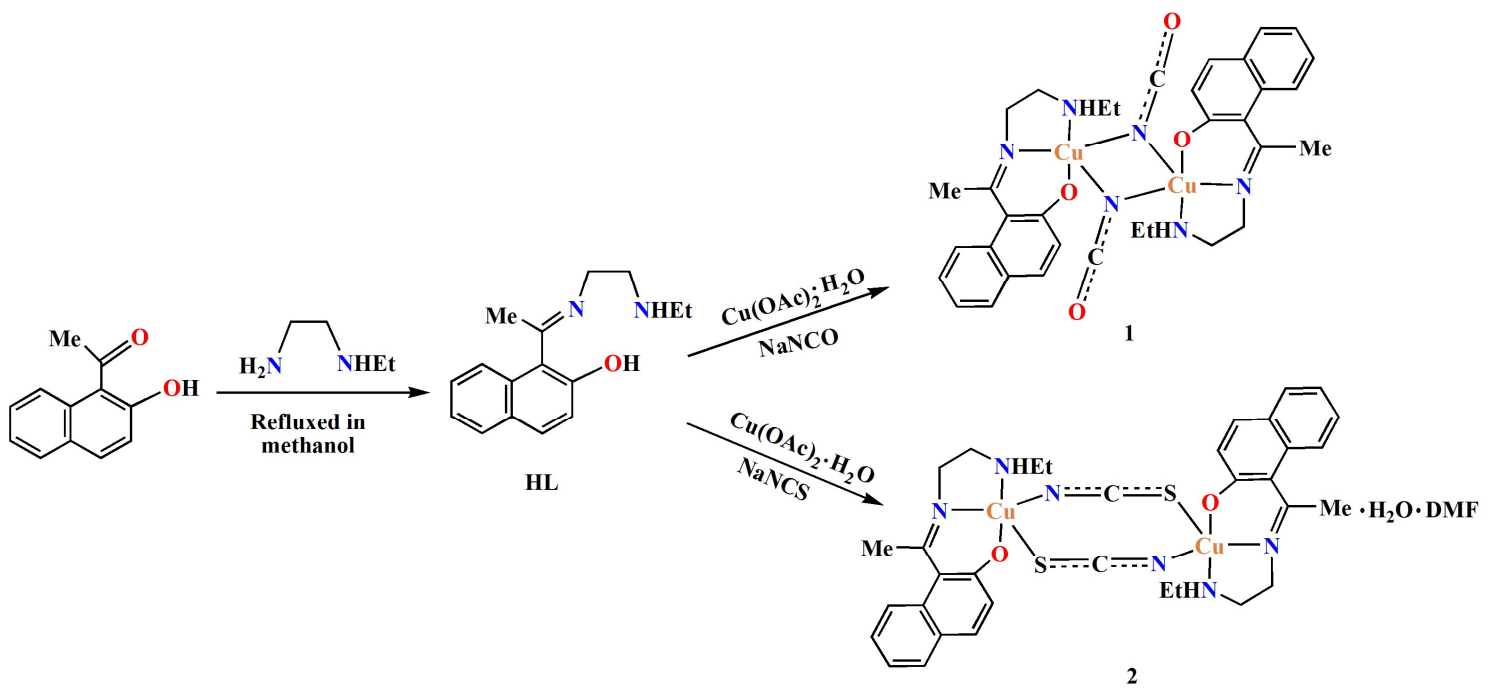

Scheme 1: Synthetic route to complexes

The reaction with cyanate and thiocyanate produced double end-on and end-to-end bridged copper(II) dimers, respectively. The structures of both complexes have been determined by single crystal X-ray diffraction analysis. The crystallographic and refinement data of both complexes are displayed in Table 1.

Table 1: Crystal data and refinement details of complexes 1 and 2.

\begin{tabular}{ccc}
\hline Complex & $\mathbf{1}$ & $\mathbf{2}$ \\
\hline Formula & $\mathrm{C}_{34} \mathrm{H}_{38} \mathrm{Cu}_{2} \mathrm{~N}_{6} \mathrm{O}_{4}$ & $\mathrm{C}_{40} \mathrm{H}_{56} \mathrm{Cu}_{2} \mathrm{~N}_{8} \mathrm{O}_{6} \mathrm{~S}_{2}$ \\
Formula weight & 721.78 & 936.12 \\
Temperature(K) & 100 & 100 \\
Crystal system & Monoclinic & Monoclinic \\
Space group & $P 2_{1} / \mathrm{c}$ & $P 2_{1} / \mathrm{n}$ \\
$\mathrm{a}(\AA)$ & $11.4708(6)$ & $15.5100(4)$ \\
$\mathrm{b}(\AA)$ & $14.4673(7)$ & $7.1497(3)$ \\
$\mathrm{c}(\AA)$ & $9.4198(5)$ & $19.7873(5)$ \\
$\beta\left(^{\circ}\right)$ & $98.641(2)$ & $101.121(2)$
\end{tabular}




$\begin{array}{ccc}\mathrm{Z} & 2 & 2 \\ \mathrm{~d}_{\text {calc }}\left(\mathrm{g} \mathrm{cm}^{-3}\right) & 1.551 & 1.444 \\ \mu\left(\mathrm{mm}^{-1}\right) & 1.426 & 1.140 \\ \mathrm{~F}(000) & 748 & 980 \\ \text { Total reflections } & 31312 & 23622 \\ \text { Unique reflections } & 3554 & 4551 \\ \text { Observed data }[\mathrm{I}>2 \sigma(\mathrm{I})] & 3310 & 3977 \\ \mathrm{R}(\text { int }) & 0.023 & 0.023 \\ \mathrm{R} 1, \text { wR2 (all data }) & 0.0231,0.0562 & 0.0281,0.0748 \\ \mathrm{R} 1, \text { wR2 }[\mathrm{I}>2 \sigma(\mathrm{I})] & 0.0207,0.0550 & 0.0243,0.0738\end{array}$

The difference in structures of both complexes may be related with the size of pseudohalide co-ligands. Small cyanate prefers to bind in end-on fashion. This end-on bridged dimer gets extra-stability due to intra-dinuclear hydrogen bonding interactions. On the other hand, the larger thiocyanate prefers to bind copper centres in end-to-end fashion. The bridging ability of thiocyanate also favours to connect copper centres in end-to-end fashion.

\section{Description of structures}

\section{Complexes $\left[\mathrm{Cu}_{2}(\mathrm{~L})_{2}\left(\mu_{1,1}-\mathrm{NCO}\right)_{2}\right](\mathbf{1})$}

Single crystal X-ray crystallography reveals that complex $\mathbf{1}$ is a centrosymmetric dimer and crystallizes in the monoclinic space group $P 2_{1} / c$. The asymmetric unit contains a copper(II) centre, which adopts a elongated (4+1) square pyramidal geometry, bonded to three donor atoms $(\mathrm{N}, \mathrm{N}, \mathrm{O})$ of the deprotonated tridentate Schiff base $\left(\mathrm{L}^{-}\right)$and end-on bridging cyanate ligand. The perspective view of complex 1 with selective atom numbering scheme is depicted in Fig. 1. 


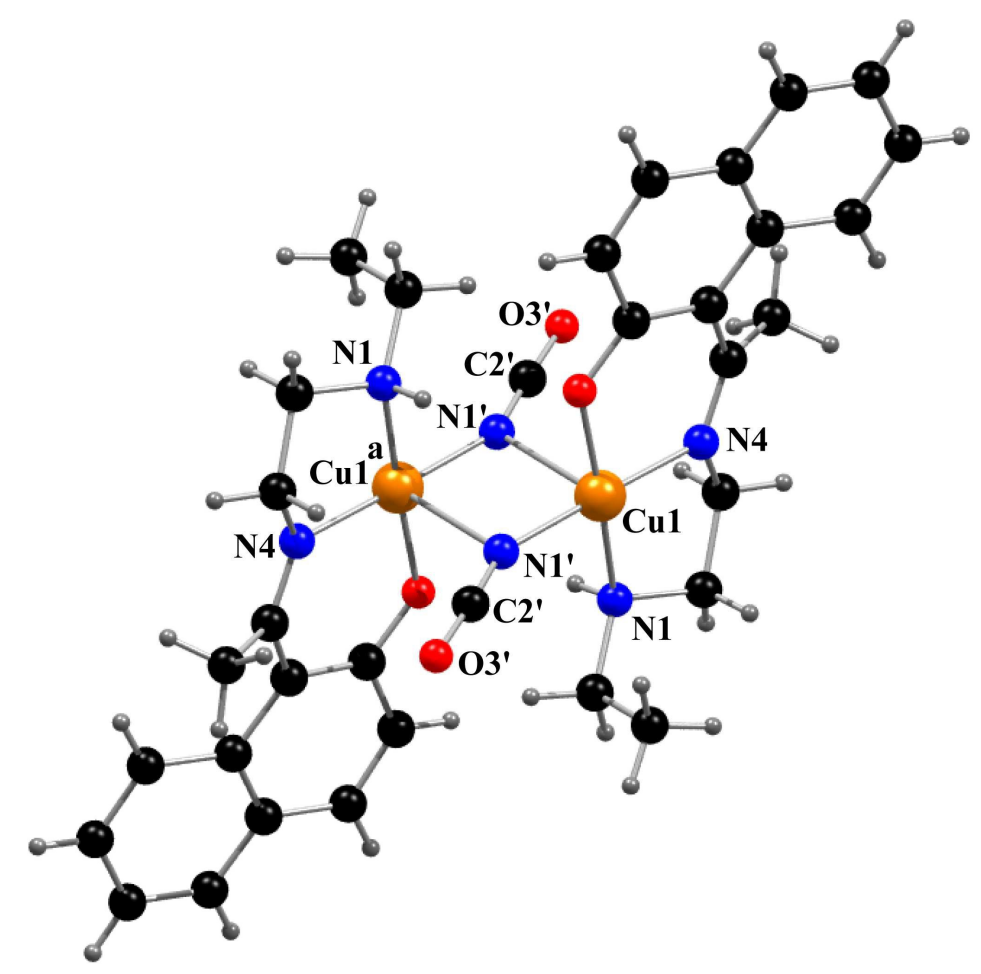

Fig. 1: Perspective view of complex 1 with selective atom numbering scheme. Hydrogen atoms have been omitted for clarity. Symmetry transformation: ${ }^{\mathrm{a}}=1-\mathrm{x}, 1-\mathrm{y}, 1-\mathrm{z}$.

The Addison parameter ${ }^{13}$ (trigonality index, $\tau=(\alpha-\beta) / 60$, where $\alpha$ and $\beta$ are the two largest $\mathrm{L}-\mathrm{M}-\mathrm{L}$ angles of the coordination sphere) is zero for a perfectly square pyramidal and is one for a perfectly trigonal bipyramidal complex. The Addison parameter value $(\tau)$ is 0.102 indicating the coordination sphere around copper(II) centre very close to ideal square-pyramidal geometry. As usual for square pyramidal structures, copper(II) centres are slightly pulled out of the mean square planes towards the apical donor atoms at distances of -0.0439(3) $\AA$ in 1 . The three donor atoms of the Schiff base occupy the equatorial plane while the anionic ligand in the dimer occupies an equatorial position in one copper coordination sphere and an axial position at a longer distance in the other. The $\mathrm{Cu}-\mathrm{N}_{\text {imine }}$ distance (1.936(4) $\AA$ ) is significantly shorter than the $\mathrm{Cu}-\mathrm{N}_{\text {amine }}$ distance $(2.028(5) \AA)$, as was observed in similar complexes. ${ }^{14}$ The five membered chelate ring $\mathrm{Cu}(1)-\mathrm{N}(1)-\mathrm{C}(2)-\mathrm{C}(3)-\mathrm{N}(4)$ assumes an intermediate conformation between half- 
chair and envelope being twisted on $\mathrm{C}(2)-\mathrm{C}(3)$ with puckering parameters ${ }^{15} \mathrm{q}(2)=0.4152(14) \AA$ and $\phi(2)=265.81(15)^{\circ}$. Deviations of the coordinating atoms, $\mathrm{N}(1), \mathrm{N}(4), \mathrm{O}(7)$ and $\mathrm{N}\left(1^{\prime}\right)$, from the least-square basal planes are $0.0765(12),-0.0579(12), 0.0811(10)$ and $-0.0558(13) \AA$. The bridging pseudo-halide is quasi-linear with the $\mathrm{N}-\mathrm{C}-\mathrm{O}$ angle being $177.4(2)^{\circ}$. The intra-dimer $\mathrm{Cu} \cdots \mathrm{Cu}$ distance is 3.2354(4) A. Selected bond lengths and angles are given in Tables 2 and 3 , respectively.

Table 2: Selected bond lengths ( $\AA$ ) around the copper(II) in complexes 1 and 2.

\begin{tabular}{ccc}
\hline Complex & $\mathbf{1}$ & $\mathbf{2}$ \\
\hline $\mathrm{Cu}(1)-\mathrm{O}(7)$ & $1.8963(10)$ & $1.9316(11)$ \\
$\mathrm{Cu}(1)-\mathrm{N}(1)$ & $2.0374(11)$ & $2.0457(14)$ \\
$\mathrm{Cu}(1)-\mathrm{N}\left(1^{\prime}\right)$ & $1.9375(12)$ & $1.9635(14)$ \\
$\mathrm{Cu}(1)-\mathrm{N}(4)$ & $1.9504(12)$ & $1.9572(13)$ \\
$\mathrm{Cu}(1)-\mathrm{N}\left(1^{\prime}\right)^{\mathrm{a}}$ & $2.7216(13)$ & $1.958(3)$ \\
$\mathrm{Cu}(1)-\mathrm{S}\left(3^{\prime}\right)^{\mathrm{a}}$ & - & $2.7729(5)$ \\
\hline
\end{tabular}

The hydrogen atom, $\mathrm{H}(1)$, attached to the amine nitrogen atom, $\mathrm{N}(1)$, forms intra dimer hydrogen bond with the symmetry related $\left({ }^{\mathrm{a}}=1-\mathrm{x}, 1-\mathrm{y}, 1-\mathrm{z}\right)$ phenoxo oxygen atom, $\mathrm{O}(7)^{\mathrm{a}}$, depicted in Fig. 2. The details of hydrogen bonding interactions are depicted in Table 4. 


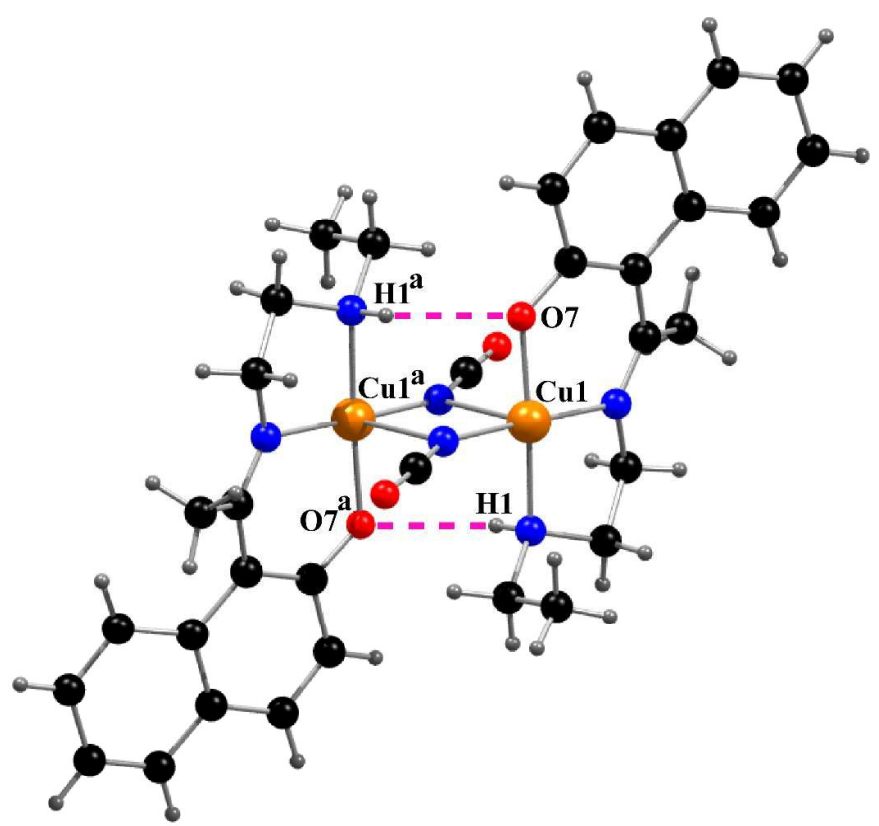

Fig. 2: Intra-dimeric hydrogen bonding interaction in complex 1. Symmetry transformation, ${ }^{\mathrm{a}}=$ $1-\mathrm{x}, 1-\mathrm{y}, 1-\mathrm{z}$

The phenyl rings $[\mathrm{C}(6)-\mathrm{C}(7)-\mathrm{C}(8)-\mathrm{C}(9)-\mathrm{C}(10)-\mathrm{C}(15)]$ and $[\mathrm{C}(10)-\mathrm{C}(11)-\mathrm{C}(12)-\mathrm{C}(13)-$ $\mathrm{C}(14)-\mathrm{C}(15)]$, is involved in intermolecular $\pi \cdots \pi$ interactions with the symmetry related (2-x,1$\mathrm{y}, 2-\mathrm{z})$ phenyl ring $\mathrm{C}(10)-\mathrm{C}(11)-\mathrm{C}(12)-\mathrm{C}(13)-\mathrm{C}(14)-\mathrm{C}(15)$, leading to the formation of $1 \mathrm{D}$ chain (Fig. 3). The geometric features of $\pi \cdots \pi$ and $\mathrm{C}-\mathrm{H} \cdots \pi$ interactions are gathered in Tables 5 and 6 , respectively.

Table 3: Selected bond angles $\left({ }^{0}\right)$ around copper(II) in complexes $\mathbf{1}$ and $\mathbf{2}$.

\begin{tabular}{ccc}
\hline Complex & $\mathbf{1}$ & $\mathbf{2}$ \\
\hline $\mathrm{O}(7)-\mathrm{Cu}(1)-\mathrm{N}(1)$ & $172.62(5)$ & $164.89(5)$ \\
$\mathrm{O}(7)-\mathrm{Cu}(1)-\mathrm{N}\left(1^{\prime}\right)$ & $88.76(5)$ & $90.32(5)$ \\
$\mathrm{O}(7)-\mathrm{Cu}(1)-\mathrm{N}(4)$ & $92.24(4)$ & $90.39(5)$ \\
$\mathrm{O}(7)-\mathrm{Cu}(1)-\mathrm{N}\left(1^{\prime}\right)^{\mathrm{a}}$ & $90.71(4)$ & $98.69(4)$ \\
$\mathrm{N}(1)-\mathrm{Cu}(1)-\mathrm{N}\left(1^{\prime}\right)$ & $93.05(5)$ & $92.52(6)$ \\
$\mathrm{N}(1)-\mathrm{Cu}(1)-\mathrm{N}(4)$ & $86.05(5)$ & $85.53(5)$
\end{tabular}




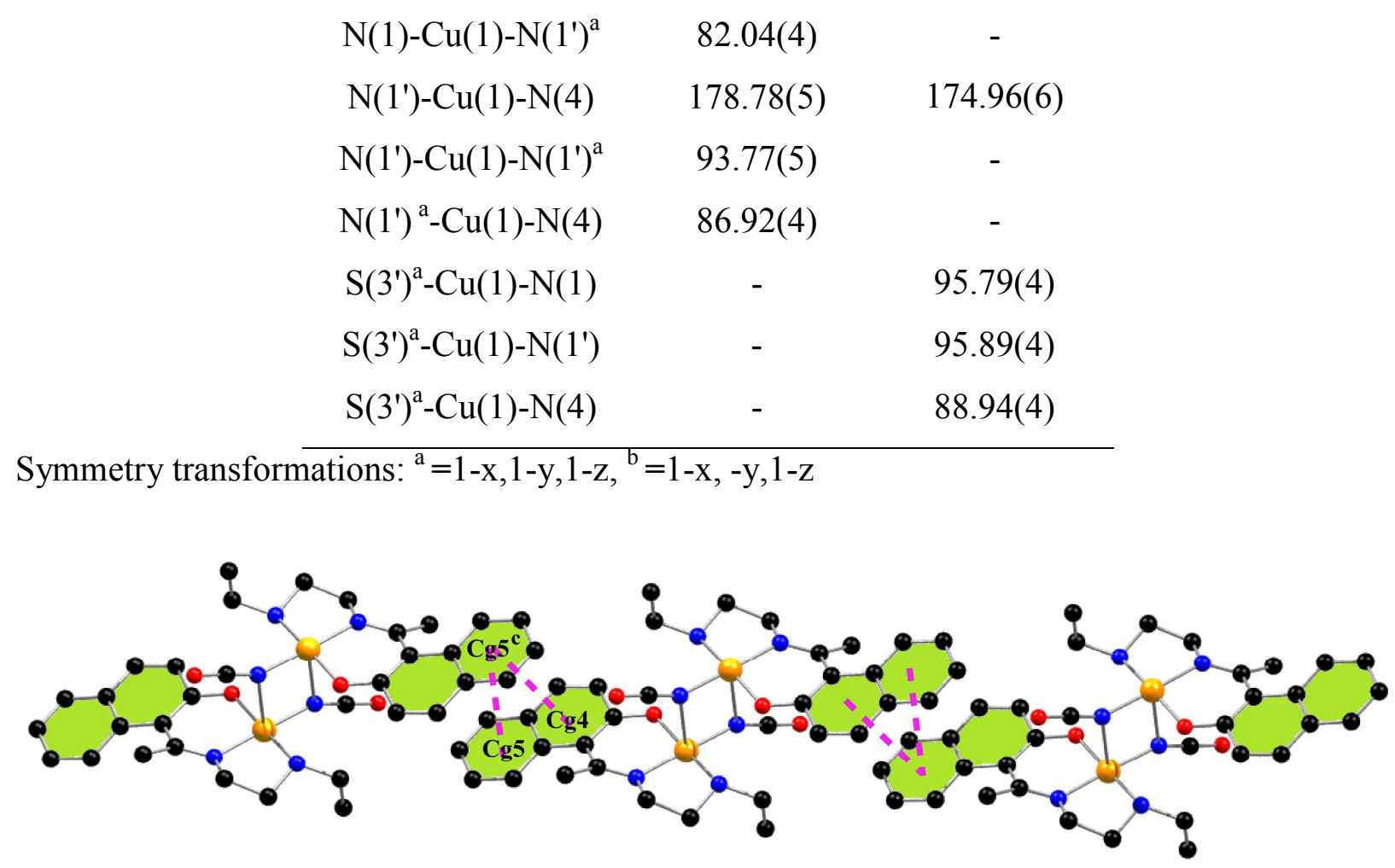

Fig. 3: Supramolecular one-dimensional chain of complex 1 formed via $\pi \cdots \pi$ interactions. $\mathrm{Cg}(4)$ and $\mathrm{Cg}(5)$ represent the centre of gravity of the rings $[\mathrm{C}(6)-\mathrm{C}(7)-\mathrm{C}(8)-\mathrm{C}(9)-\mathrm{C}(10)-\mathrm{C}(15)]$ and [C(10)-C(11)-C(12)-C(13)-C(14)-C(15)] for complex 1. Hydrogen atoms have been omitted for clarity.

Table 4: Geometric parameters for H-bonding interactions for complexes $\mathbf{1}$ and $\mathbf{2 .}$

\begin{tabular}{|c|c|c|c|c|c|}
\hline Complex & $\mathbf{D}-\mathbf{H} \cdots \mathbf{A}$ & D-H (Å) & $\mathbf{H} \cdots \mathbf{A}(\AA)$ & $\mathbf{D} \cdots \mathbf{A}(\AA)$ & $\angle \mathrm{D}-\mathrm{H} \cdots \mathbf{A}\left(^{\circ}\right)$ \\
\hline \multirow[t]{2}{*}{1} & $\mathrm{~N}(1)-\mathrm{H}(1) \cdots \mathrm{O}(7)^{\mathrm{a}}$ & $0.876(18)$ & $2.374(18)$ & $3.0665(15)$ & $136.1(15)$ \\
\hline & $\mathrm{N}(1)-\mathrm{H}(1) \cdots \mathrm{O}(1 \mathrm{~W})^{\mathrm{a}}$ & $0.84(2)$ & $2.33(2)$ & $3.0762(19)$ & $148.3(17)$ \\
\hline \multirow[t]{2}{*}{2} & $\mathrm{O}(1 \mathrm{~W})-\mathrm{H}(1 \mathrm{~W}) \cdots \mathrm{O}(7)$ & $0.79(3)$ & $2.11(3)$ & $2.8664(17)$ & $161(3)$ \\
\hline & $\mathrm{O}(1 \mathrm{~W})-\mathrm{H}(2 \mathrm{~W}) \cdots \mathrm{O}(1 \mathrm{~L})$ & $0.83(2)$ & $1.97(2)$ & $2.797(2)$ & $171(2)$ \\
\hline
\end{tabular}

D, donor; H, hydrogen; A, acceptor. Symmetry transformation ${ }^{\mathrm{a}}=1-\mathrm{x}, 1-\mathrm{y}, 1-\mathrm{z}$. 
Table 5: Geometric features (distances, $\AA$ and angles, ${ }^{\circ}$ ) of the $\pi \cdots \pi$ stacking interactions in complexes 1 and 2.

\begin{tabular}{cccccc}
\hline Complex & $\mathbf{C g}(\operatorname{Ring} \mathbf{I}) \cdots \mathbf{C g}(\operatorname{Ring} \mathbf{J})$ & $\mathbf{C g} \cdots \mathbf{C g}(\AA)$ & $\boldsymbol{\alpha}\left(^{\circ}\right)$ & $\mathbf{C g}(\mathbf{I}) \cdots \operatorname{Perp}(\AA)$ & $\mathbf{C g}(\mathbf{J}) \cdots \operatorname{Perp}(\AA)$ \\
\hline & $\mathrm{Cg}(4) \cdots \operatorname{Cg}(5)^{\mathrm{c}}$ & $3.9495(8)$ & $5.41(7)$ & $3.7118(6)$ & $3.6043(6)$ \\
$\mathbf{1}$ & $\mathrm{Cg}(5) \cdots \operatorname{Cg}(5)^{\mathrm{c}}$ & $3.8972(9)$ & 0 & $3.6342(6)$ & $3.6341(6)$
\end{tabular}

Symmetry transformations: ${ }^{\mathrm{c}}=2-\mathrm{x}, 1-\mathrm{y}, 2-\mathrm{z}$.

$\alpha=$ Dihedral angle between ring I and ring $\mathrm{J} . \mathrm{Cg}(\mathrm{I}) \cdots$ Perp $=$ Perpendicular distance of $\mathrm{Cg}(\mathrm{I})$ on ring J. $\mathrm{Cg}(\mathrm{J}) \cdots$ Perp $=$ Perpendicular distance of $\mathrm{Cg}(\mathrm{J})$ on ring $\mathrm{I} . \mathrm{Cg}(4)=$ Centre of gravity of the ring $[\mathrm{C}(6)-\mathrm{C}(7)-\mathrm{C}(8)-\mathrm{C}(9)-\mathrm{C}(10)-\mathrm{C}(15)] ; \mathrm{Cg}(5)=$ Centre of gravity of the ring $[\mathrm{C}(10)-\mathrm{C}(11)-$ $\mathrm{C}(12)-\mathrm{C}(13)-\mathrm{C}(14)-\mathrm{C}(15)]$.

$\left[\mathrm{Cu}_{2}(\mathrm{~L})_{2}\left(\mu_{1,3}-\mathrm{NCS}\right)_{2}\right] \cdot \mathrm{DMF} \cdot \mathrm{H}_{2} \mathrm{O}(\mathbf{2})$

Single crystal X-ray crystallography reveals that complex $\mathbf{2}$ is also a centrosymmetric dimer and it crystallizes in the triclinic space group $P 2_{1} / n$. The asymmetric unit contains a square pyramidal copper(II) centre bonded to three donor atoms $(\mathrm{N}, \mathrm{N}, \mathrm{O})$ of the deprotonated tridentate Schiff base $\left(\mathrm{L}^{-}\right)$and end-on bridging anionic ligand cyanate leading to elongated (4+1) square pyramidal geometry. The perspective view of complex 2 with selective atom numbering scheme is depicted in Fig. 4. The Addison parameter value $[\tau=0.167]$ indicates that the coordination sphere of copper(II) centre is close to the ideal square-pyramidal geometry. As usual for square pyramidal structures, copper(II) centres are slightly pulled out of the mean square planes towards the apical donor atoms at distance of -0.1349(2) $\AA$ in $\mathbf{2}$. The three donor atoms of the Schiff base occupy the equatorial plane while each of the anionic ligand in the dimer occupies an equatorial position in one copper coordination sphere and an axial position at a longer distance in the other. 
The $\mathrm{Cu}-\mathrm{N}_{\text {imine }}$ distance is significantly shorter $1.922(3) \AA$ than the $\mathrm{Cu}-\mathrm{N}_{\text {amine }}$ distance 2.036(4) $\AA$ for 2, as observed in similar complexes. ${ }^{14}$ The copper(II)-nitrogen(anion) bond lengths in the equatorial plane range from 1.937(4)-1.979(5) $\AA$, while the copper(II)-nitrogen(anion) axial bond lengths range from $2.442(5)-2.692(4) \AA$. The five membered chelate ring $\mathrm{Cu}(1)-\mathrm{N}(1)-\mathrm{C}(2)-$ $\mathrm{C}(3)-\mathrm{N}(4)$ assumes intermediate conformation between half-chair and envelope being twisted on $\mathrm{N}(1)-\mathrm{C}(2)$ with puckering parameters $\mathrm{q}(2)=0.4307(16) \AA$ and $\phi(2)=263.97(16)^{\circ}$. Deviations of the coordinating atoms, $\mathrm{N}(1), \mathrm{N}(4), \mathrm{O}(7)$ and $\mathrm{N}\left(1^{\prime}\right)$, from the least-square basal planes are 0.1165(14), -0.0556(12), 0.1221(11), and -0.0481(14) $\AA$. The bridging $\mathrm{Cu}_{2} \mathrm{~N}_{2}$ network is planar. The bridging pseudo-halides are quasi-linear with the $\mathrm{N}-\mathrm{C}-\mathrm{S}$ angle being $179.3(1)^{\circ}$. The intra dimer $\mathrm{Cu} \cdots \mathrm{Cu}$ distance is 5.6382(4) $\AA$. Selected bond lengths and angles are given in Tables 2 and 3 , respectively.

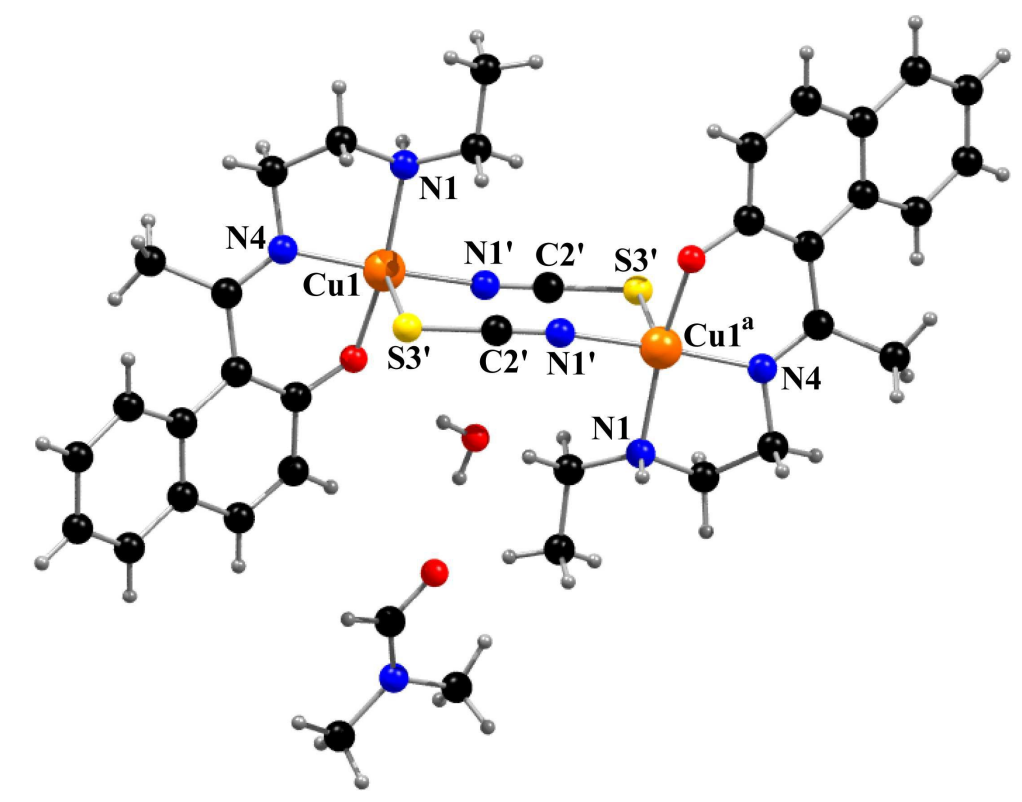

Fig. 4: Perspective view of complex 2 with selective atom numbering scheme. Hydrogen atoms have been omitted for clarity except solvent molecules. Symmetry transformation: ${ }^{\mathrm{a}}=1-\mathrm{x},-\mathrm{y}, 1-\mathrm{z}$. 
The hydrogen atoms $\mathrm{H}(1 \mathrm{~W})$ and $\mathrm{H}(2 \mathrm{~W})$, attached to the oxygen atom $\mathrm{O}(1 \mathrm{~W})$, are involved in hydrogen bonding interactions with the symmetry related the symmetry related phenoxo oxygen atom, $\mathrm{O}(7)^{\mathrm{a}}$ and oxygen atom, $\mathrm{O}(1 \mathrm{~L})^{\mathrm{a}}\left(^{\mathrm{a}}=1-\mathrm{x}, 1-\mathrm{y}, 1-\mathrm{z}\right)$, respectively. The hydrogen atom $\mathrm{H}(1)$, attached to nitrogen atom $\mathrm{N}(1)$, is engaged in bifurcated hydrogen bonding interactions with the symmetry related oxygen atoms $\mathrm{O}(1 \mathrm{~W})^{\mathrm{a}}$ and phenoxo oxygen atom, $\mathrm{O}(7)^{\mathrm{a}}$, $\left({ }^{\mathrm{a}}=1-\mathrm{x}, 1-\mathrm{y}, 1-\mathrm{z}\right)$ leading to the formation of a chain (Fig. 5). The geometric features of C-H $\cdots \pi$ interactions are given in Table 6.

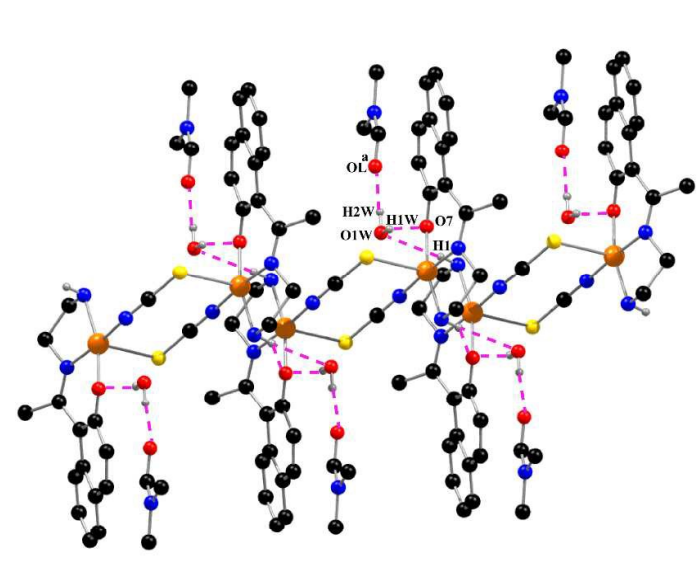

(a)

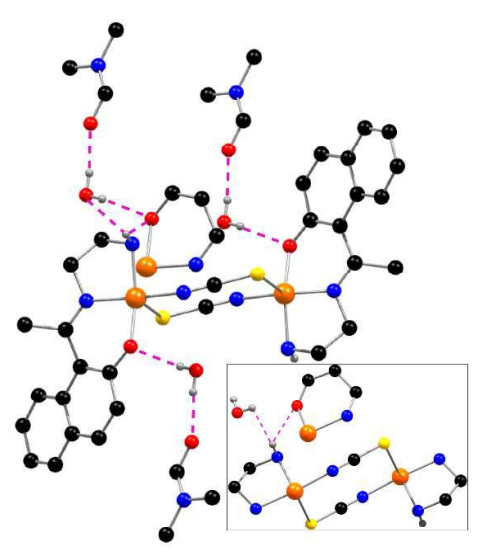

(b)

Fig. 5: (a) One-dimensional hydrogen bonded chain structure of complex 2. (b) Highlighted H-bonding interactions. Selected hydrogen atoms and ethyl group have been omitted for clarity. Symmetry transformation, ${ }^{\mathrm{a}}=1-\mathrm{x},-\mathrm{y}, 1-\mathrm{z}$.

Table 6: Geometric features (distances in $\AA$ and angles in ${ }^{\circ}$ ) of the $\mathrm{C}-\mathrm{H} \cdots \pi$ interactions obtained for complexes 1 and $\mathbf{2}$.

\begin{tabular}{ccccc}
\hline Complex & $\mathbf{C}-\mathbf{H} \cdots \mathbf{C g}(\mathbf{R i n g})$ & $\mathbf{H} \cdots \mathbf{C g}$ & $\mathbf{C}-\mathbf{H} \cdots \mathbf{C g}\left(^{\circ}\right)$ & $\mathbf{C} \cdots \mathbf{C g}(\mathbf{A})$ \\
\hline $\mathbf{1}$ & $\mathrm{C}(16)-\mathrm{H}(16 \mathrm{C}) \cdots \mathrm{Cg}(5)^{\mathrm{d}}$ & 2.96 & 162 & $3.9081(16)$ \\
& $\mathrm{C}(3 \mathrm{~L})-\mathrm{H}(3 \mathrm{LA}) \cdots \mathrm{Cg}(4)^{\mathrm{e}}$ & 2.81 & 144 & $3.651(2)$
\end{tabular}




$2 \begin{array}{cccc}\mathrm{C}(3 \mathrm{~L})-\mathrm{H}(3 \mathrm{LB}) \cdots \mathrm{Cg}(4)^{\mathrm{f}} & 2.74 & 149 & 3.618(2) \\ \mathrm{C}(4 \mathrm{~L})-\mathrm{H}(4 \mathrm{LA}) \cdots \mathrm{Cg}(3)^{\mathrm{e}} & 2.73 & 141 & 3.544(2) \\ \mathrm{C}(4 \mathrm{~L})-\mathrm{H}(4 \mathrm{LC}) \cdots \mathrm{Cg}(3)^{\mathrm{f}} & 2.89 & 131 & 3.615(2)\end{array}$

Symmetry transformations: ${ }^{d}=x, 1 / 2-y,-1 / 2+z ; \quad=3 / 2-x, 1 / 2+y, 1 / 2-z ; \quad f=3 / 2-x,-1 / 2+y, 1 / 2-z$

For complex 1: $\mathrm{Cg}(5)=$ Centre of gravity of the ring [C(10)-C(11)-C(12)-C(13)-C(14)-C(15)];

For complex 2: $\mathrm{Cg}(4)=$ Centre of gravity of the ring [C(10)-C(11)-C(12)-C(13)-C(14)-C(15)];

$\mathrm{Cg}(3)=$ Centre of gravity of the ring $[\mathrm{C}(6)-\mathrm{C}(7)-\mathrm{C}(8)-\mathrm{C}(9)-\mathrm{C}(10)-\mathrm{C}(15)]$.

\section{IR and electronic spectra}

In the IR spectra of complexes 1 and 2, strong and sharp bands around $1610 \mathrm{~cm}^{-1}$ were routinely noticed due to azomethine $(\mathrm{C}=\mathrm{N})$ groups of Schiff bases. ${ }^{16}$ One moderately strong band in the region of $3200-3228 \mathrm{~cm}^{-1}$ in the IR spectrum of both complexes may be assigned to N-H stretching vibration. ${ }^{17}$ The bands in the range of $2985-2860 \mathrm{~cm}^{-1}$ may be assigned to as alkyl C-H bond stretching vibrations. ${ }^{18}$ One sharp and strong band at $2209 \mathrm{~cm}^{-1}$ in the IR spectrum of $\mathbf{1}$ indicates the presence of the $\mathrm{N}$ bonded cyanate group. ${ }^{19}$ The $\mu-1,3$ bridging mode of the thiocyanate group in complex $\mathbf{2}$ is confirmed by the splitting of the absorption band corresponding to the $\gamma_{\mathrm{C}=\mathrm{N}}$ asymmetric stretching at 2103 and $2053 \mathrm{~cm}^{-1}$ indicates the S- and Ncoordination modes of the thiocyanate ligand respectively. ${ }^{20,21}$ Two medium bands at 831 and $762 \mathrm{~cm}^{-1}$ may be attributed to $\mathrm{v}(\mathrm{CS}) .^{21}$

The broad absorption bands around $595 \mathrm{~nm}$ were observed for both complexes i.e. in the visible region due to $\mathrm{d}-\mathrm{d}$ transitions. The absorption bands around $310 \mathrm{~nm}$ may be assigned to 
intraligand $\pi^{*} \leftarrow \mathrm{n}$ transitions of azomethine $(\mathrm{C}=\mathrm{N})$ function of Schiff base. ${ }^{22}$ The band around $390 \mathrm{~nm}$ may be attributed to LMCT transition. ${ }^{23}$

\section{Magnetic properties}

Variable temperature $(2-300 \mathrm{~K})$ magnetic susceptibility data were collected for microcrystalline samples of both complexes. The agreement factor $\mathrm{R}$ is defined as $\mathrm{R}$ $=\Sigma_{\mathrm{i}}\left[\left(\chi_{\mathrm{M}} \mathrm{T}\right)_{\text {obsd }^{-}}\left(\chi_{\mathrm{M}} \mathrm{T}\right)_{\text {calcd }}\right]^{2} / \Sigma_{\mathrm{i}}\left[\left(\chi_{\mathrm{M}} \mathrm{T}\right)_{\mathrm{obsd}}\right]^{2}$. The temperature independent paramagnetism (TIP) was taken as $-338 \times 10^{-6}$ and $-369 \times 10^{-6} \mathrm{~cm}^{3} \mathrm{~K} \mathrm{~mol}^{-1}$ for complexes $\mathbf{1}$ and $\mathbf{2}$, respectively.

Since both complexes consist of isolated copper(II) dimers with double pseudo-halide bridges, a simple Bleaney-Bowers dimer model for two $S=1 / 2$ ions was used to fit the magnetic data. This model reproduces very satisfactorily magnetic properties in the whole temperature range. Therefore, the magnetic behaviour $\left(\chi_{M} T\right.$ vs $T$ and $\chi_{M}$ vs $T$ plots $)$ was simulated using the standard Heisenberg-Dirac-van Vleck Hamiltonian, $\hat{H}=-2 J \mathrm{~S}_{1} \cdot \mathrm{S}_{2}+\mu_{\mathrm{B}} g S H$, where all the parameters have their usual meanings.

\section{Complex 1}

A $\chi_{M} T$ versus $T$ plot $\left(\chi_{M}\right.$ is the molar susceptibility for two copper(II) ions) for complex $\mathbf{1}$ is shown in Fig. 6. The value of $\chi_{\mathrm{M}} \mathrm{T}$ for $\mathbf{1}$ at $300 \mathrm{~K}$ is $0.834 \mathrm{~cm}^{3} \mathrm{~K} \mathrm{~mol}^{-1}$, which is as expected for two magnetically quasi-isolated spin doublets $(g>2.00)$. The $\chi_{M} T$ values remains practically constant from $25-300 \mathrm{~K}$. Below $25 \mathrm{~K}$, there is an abrupt increase of $\chi_{\mathrm{M}} \mathrm{T}$, reaching a value of $1.034 \mathrm{~cm}^{3} \mathrm{~K} \mathrm{~mol}^{-1}$ at $2 \mathrm{~K}$. The $\chi_{\mathrm{M}}$ values increase monotonically when the temperature decreases (Fig. 6 ). The fit of the experimental data yields the following values: $g=2.115(2) ; J=0.97(6)$ $\mathrm{cm}^{-1} ; \mathrm{R}=5.4 \times 10^{-3}$. 


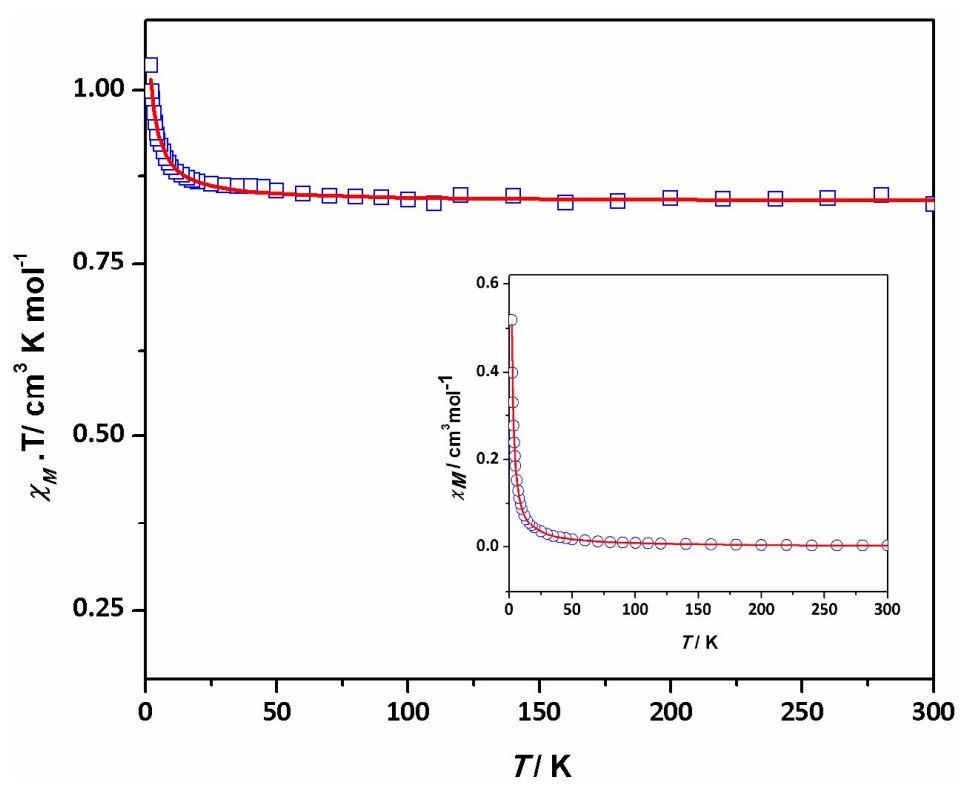

Fig. 6: Plot of $\chi_{M} T$ vs $T$ for a powder sample of complex 1 in a $1 \mathrm{~T}$ external magnetic field. Experimental data are shown as blue squares and the best fit is represented by the red line. Inset shows plot of $\chi_{M}$ vs $T$ where the experimental data are shown as blue circles and the best fit is represented by the red line.

\section{Complex 2}

The $\chi_{M} \mathrm{~T}$ and $\chi_{M}$ (inset) versus $\mathrm{T}$ plots $\left(\chi_{M}\right.$ is the molar magnetic susceptibility for two copper(II) ions) are shown in Fig. 7. The value of $\chi_{M} \mathrm{~T}$ at $300 \mathrm{~K}$ is $0.822 \mathrm{~cm}^{3} \mathrm{~K} \mathrm{~mol}^{-1}$, which is as expected for two magnetically quasi-isolated spin doublets $(g>2.00)$. The $\chi_{M} T$ values remain practically constant until around $30 \mathrm{~K}$, then decreases slowly and finally drops to $0.697 \mathrm{~cm}^{3} \mathrm{~K}$ $\mathrm{mol}^{-1}$ at $2 \mathrm{~K}$ due to antiferromagnetic exchange coupling between copper(II) centres. No maximum was found in the $\chi_{M}$ versus $\mathrm{T}$ plot. The global feature is characteristic of weak antiferromagnetic coupling. The best fit was achieved for $g=2.09(1)$ and $J=-0.6(1) \mathrm{cm}^{-1}(\mathrm{R}=$ $2.9 \times 10^{-2}$ ). The relatively high value of $\mathrm{R}$ originates probably from the strong intermolecular $\mathrm{H}-$ bonding interactions in $\mathbf{2}$. 
Fig. 7: Plot of $\chi_{M} T$ vs $T$ for a powder sample of complex 2 in a 1 T external magnetic field. Experimental data are shown as blue squares and the best fit is represented by the red line. Inset shows plot of $\chi_{M}$ vs $T$ where the experimental data are shown as blue circles and the best fit is represented by the red line.

\section{Magneto-structural correlation}

Complex $\mathbf{1}$ is a double end-on cyanate bridged dinuclear copper(II) complex with a tridentate $\mathrm{N}_{2} \mathrm{O}$ donor Schiff base. Although $\mathrm{Cu}-\mathrm{N}-\mathrm{Cu}$ angle is the key factor in determining the sign of J value, when pseudo-halide ligand bridges two copper(II) centres in end-on, basal-basal manner, ${ }^{24}$ there is no meaningful correlation between $\mathrm{Cu}-\mathrm{N}-\mathrm{Cu}$ angle and $J$ value in in basalapical pseudo-halide bridged dinuclear copper(II) complexes. ${ }^{25}$ This is because the single unpaired electron of copper(II) resides in $\mathrm{dx}^{2}-\mathrm{y}^{2}$ orbital, which lies essentially in the basal plane (XY plane) of the copper(II) centre having square pyramidal geometry; and therefore the magnetic orbital has only a small contribution in the direction of Z-axis (i.e. in the direction of second copper(II) linked via pseudo-halide bridge). Thus there is practically no overlap between the magnetic orbitals. Therefore the weak interactions amongst the copper(II) centres in end-on basal-apical cyanate bridged dinuclear complex $\mathbf{1}$ may be linked with the square pyramidal geometry of copper(II) centre. Table 7 gathers all end-on cyanate bridged and a few pseudohalide bridged dinuclear copper(II) complexes along with $\tau$ values of copper(II) centres. Lower value of $\tau$ indicate less deviation from ideal square pyramidal geometry, and may be expected to have lower value of $J .^{5}$ However, this simple theory does not seem to be appropriate, as is evident from the data listed in Table 7. 
Table 7: Main structural and magnetic parameters for end-on bridged copper(II) complexes with tridentate $\mathrm{N}_{2} \mathrm{O}$ donor Schiff bases

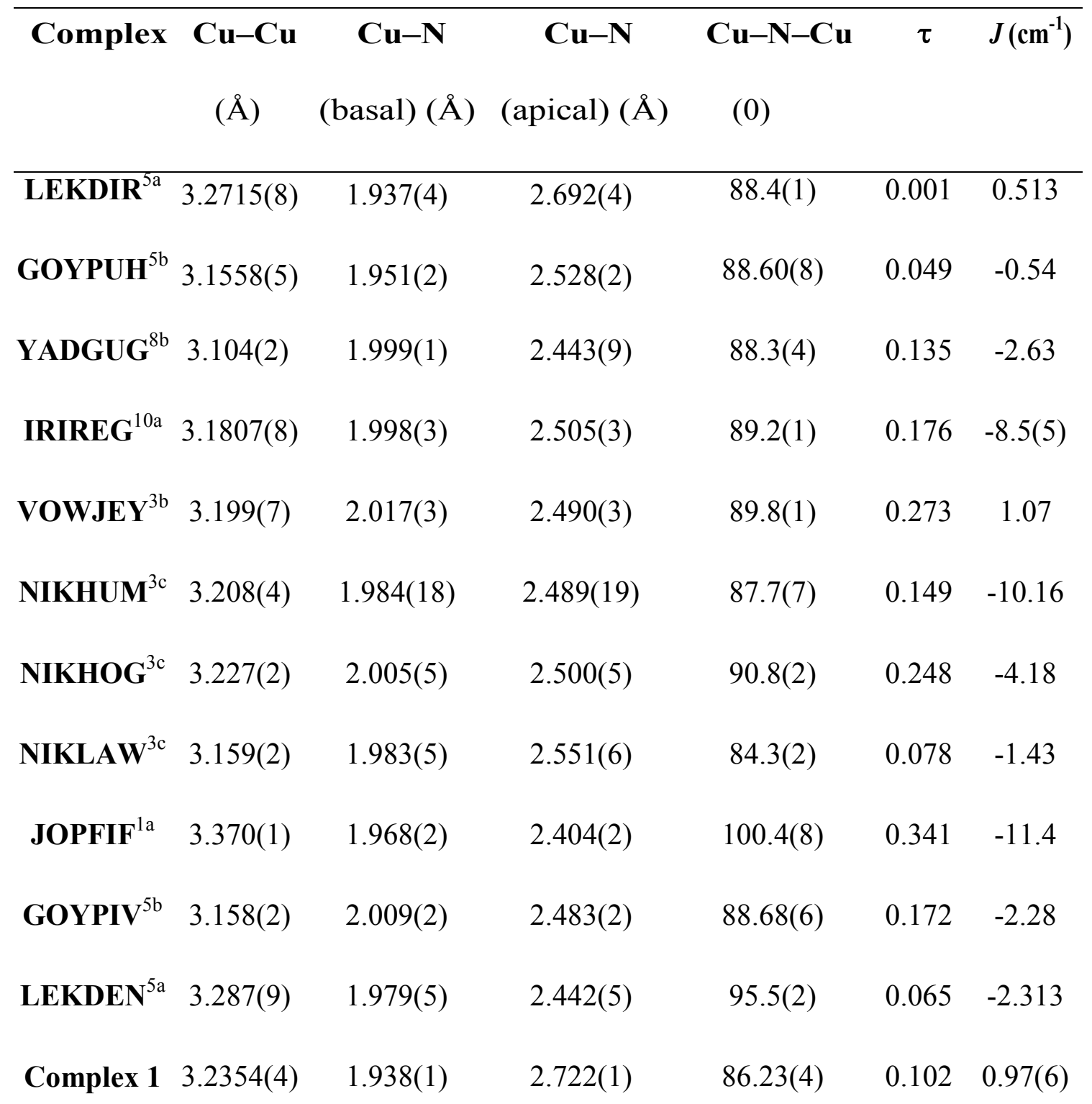

On the other hand, complex 2 features an end-to-end thiocyanate bridged dimer. The weak antiferromagnetic coupling $\left(J=-0.6(1) \mathrm{cm}^{-1}\right)$ is obviously due to the longer distance (5.6382(4) A) among copper(II) centres. Only one similar dinuclear copper(II) complex with 
Schiff base blocking ligand bridged by end-to-end thiocyanate is reported in literature (Table $8) .^{12 b}$

Table 8: Main structural and magnetic parameters for end-to-end bridged copper(II) complexes with tridentate $\mathrm{N}_{2} \mathrm{O}$ donor Schiff bases

\begin{tabular}{ccc}
\hline Complex & $\mathbf{C u}-\mathbf{C u}(\AA)$ & $J\left(\mathbf{c m}^{-1}\right)$ \\
\hline MAQRAY Y & $5.8629(6)$ & $-1.71(1)$ \\
Complex 2 & $5.6382(4)$ & $-0.6(1)$ \\
\hline
\end{tabular}

\section{Conclusion}

The whole work can be concluded in two statements. Firstly, the use of different pseudohalides with different bridging ability (i.e. cyanate and thiocyanate) can regulate the electronic and steric demands which could effectively modulate the structural versatility of complexes: cyanate with least bridging ability forms end-on bridged dimer, whereas thiocyanate with moderate bridging ability forms end-to-end bridged dimer. Secondly, comparison of the structures and the results of magnetic properties with previously related reported dinuclear copper(II) complexes with tridentate $\mathrm{N}_{2} \mathrm{O}$ donor Schiff bases reveals that the magnetic exchange in such systems is governed by combined effects of several parameters. Synthesis and characterization of more complexes may be needed to arrive at any concrete generalization.

\section{Notes and references}


Electronic supplementary information (ESI): Experimental details, X-ray crystallographic data and Instrumentation details, Hirshfeld surfaces and X-ray powder diffraction pattern. CCDC 1580147 and 1580148 contain the supplementary crystallographic data for complexes $\mathbf{1}$ and $\mathbf{2}$, respectively. These data can be obtained free of charge via http://www.ccdc.cam.ac.uk/conts/retrieving.html, or from the Cambridge Crystallographic Data Centre, 12 Union Road, Cambridge CB2 1EZ, UK; fax: (+44) 1223-336-033; or e-mail: deposit@,ccdc.cam.ac.uk.

1. (a) S. Jana, B. K. Shaw, P. Bhowmik, K. Harms, M. G. B. Drew, S. Chattopadhyay and S. K. Saha, Inorg. Chem. 2014, 53, 8723-8734. (b) Y. Wang, Y. -X. Che and J. -M. Zheng, Inorg. Chem. Commun., 2012, 21, 69-71; (c) L. -Z. Chen, D. -D. Huang, J. -Z. Ge and F. -M. Wang, Inorg. Chim. Acta, 2013, 406, 95-99; (d) R. Biswas, Y. Ida, M. L. Baker, S. Biswas, P. Kar, H. Nojiri, T. Ishida and A. Ghosh, Chem. Eur. J., 2013, 19, 3943-3953. (e) M. Das and S. Chattopadhyay, Polyhedron, 2013, 50, 443-451.

2. (a) C. Biswas, S. Chattopadhyay, M. G. B. Drew and A. Ghosh, Polyhedron, 2007, 26, 44114418; (b) H. Y. Zang, Y. Q. Lan, G. S. Yang, X. L. Wang, K. Z. Shao, G. J. Xu and Z. M. Su, CrystEngComm., 2010, 12, 434-445; (c) M. Das, S. Chatterjee and S. Chattopadhyay, Polyhedron, 2014, 68, 205-211; (d) Z. N. Chen, H. X. Zhang, K. B. Yu, K. C. Zheng, H. Cai and B. S. Kang, J. Chem. Soc., Dalton Trans., 1998, 1133-1136; (e) A. Bacchi, M. Carcelli, T. Chiodo and P. Pelagatti, CrystEngComm., 2010, 12, 4226-4230;

3. (a) S. Koner, S. Saha, T. Mallah and K.-I. Okamoto, Inorg. Chem., 2004, 43, 840-842; (b) P. P. Chakrabarty, S. Giri, D. Schollmeyer, H. Sakiyama, M. Mikuriya, A. Sarkar and S. Saha, Polyhedron, 2015, 89, 49-54; (c) S. Mondal, P. Chakraborty, N. Aliaga-Alcalde and S. Mohanta, 
Polyhedron, 2013, 63, 96-102; (d) M. Zbiri, S. Saha, C. Adhikary, S. Chaudhuri, C. Daul and S. Koner, Inorg. Chim. Acta, 2006, 359, 1193-1199; (e) C. Adhikary, R. Sen, G. Bocelli, A. Cantoni, S. Chaudhuri and S. Koner, J. Coord. Chem., 2009, 62, 3573-3582.

4 (a) C. Adhikary and S. Koner, Coord. Chem. Rev., 2010, 254, 2933-2958 and references there in.

5. (a) A. Bhattacharyya, A. Bauzá, S. Sproules, L. S. Natrajan, A. Frontera and S. Chattopadhyay, Polyhedron 2017, 137, 332-346; (b) P. Bhowmik, A. Bhattacharyya, K. Harms, S. Sproules and S. Chattopadhyay, Polyhedron, 2015, 85, 221-231.

6. (a) Zhong-Lu You, Lin Zhang, Da-Hua Shi, Xiao-Ling Wang, Xiao-Fang Li and Yu-Ping Ma, Inorg.Chem.Commun., 2010, 13, 996-998; (b) A. Bhattacharyya, B. N. Ghosh, S. Herrero, K. Rissanen, R. Jiménez-Aparicio and S. Chattopadhyay, Dalton Trans., 2015, 44, 493-497; (c) S. Roy, A. Bhattacharyya, S. Herrero, R.Gonzalez-Prieto, A. Frontera, and S. Chattopadhyay, ChemistrySelect 2017, 2, 6535-6543.

7. (a) S. Mukherjee and P. S. Mujherjee, Acc. Chem. Res.,2013, 46, 2556-2566; (b) S. Mukherjee and P.S. Mujherjee, Dalton Trans., 2013, 42, 4019-4030; (c) P. Talukder, A. Datta, S. Mitra, G. Rosair, M. S. E. Fallah and J. Ribas, Dalton Trans., 2004, 4161-4167; (d) Rui-Hua Hui, Peng Zhou, Zhong-Lu You, Synth React Inorg Met Org nano-Met. Chem, 2009, 39, 495-495.

8. (a) S. Jana, P. Bhowmik, M. Das, P. P. Jana, K. Harms and S. Chattopadhyay, Polyhedron, 2012, 37, 21-26; (b) M. S. Ray, A. Ghosh, S. Chaudhuri, M. G. B. Drew and J. Ribas, Eur. J. Inorg. Chem., 2004, 3110-3117; (c) S. Paul, R. Clerac, N. G. R. Hearns and D. Ray, Cryst. Growth Des., 2009, 9, 4032-4040; 
9. S. Sikorav, I. Bkouche-Waksman and O. Kahn, Inorg. Chem. 1984, 23, 490-495.

10. (a) S. Koner, S. Saha, T. Mallah and K.-I. Okamoto, Inorg. Chem., 2004, 43, 840-842; (b) S. Mondal, P. Chakraborty, N. Aliaga-Alcalde and S. Mohanta, Polyhedron, 2013, 63, 96-102; (c) P. P. Chakrabarty, S. Giri, D. Schollmeyer, H. Sakiyama, M. Mikuriya, A. Sarkar and S.Saha, Polyhedron, 2015, 89, 49-54

11. a) Z. Shen, J. L. Zuo, Z. Yu, Y. Zhang, J. F. Bai, C. M. Che, H. K. Fun, J. J. Vittal and X. Z. You, J. Chem. Soc., Dalton Trans., 1999, 3393-3398; (b) S. Dalai, P. S. Mukherjee, T. Mallah, M. G. B. Drew and N. R. Chaudhuri, Inorg. Chem. Commun., 2002, 5, 472-474; (c) Z. Shen, J. L. Zuo, S. Gao, Y. Song, C. M. Che, H. K. Fun and X. Z. You, Angew. Chem., Int. Ed., 2000, 39, 3633-3635.

12. (a) Y. S. You, J. H. Yoon, H. C. Kim and C. S. Hong, Chem. Commun., 2005, 4116-4118; (b) S. Banerjee, M. G. B. Drew, C.-Z. Lu, J. Tercero, C. Diaz and A. Ghosh, Eur. J. Inorg. Chem., 2005, 2376-2383.

13. S. Khan, A. A. Masum, M. M. Islam, M.G.B. Drew, A. Bauzá, A. Frontera and S. Chattopadhyay, Polyhedron 2017, 123, 334-343.

14. P. K. Bhaumik, K. Harms and S. Chattopadhyay, Polyhedron, 2014, 67, 181-190.

15. D. Cremer and J. A. Pople, J. Am. Chem. Soc., 1975, 97, 1354-1358.

16. S. Khan, S. Jana, M. G. B. Drew, A. Bauzá, A. Frontera and S.Chattopadhyay, RSC Adv. 2016, 6, 61214-61220.

17. M. Das, S. Chatterjee, K. Harms, T. K. Mondal and Chattopadhyay, S. Dalton Trans. 2014, 43, 2936-2947. 
18. S. Roy, K. Harms, and S. Chattopadhyay, Polyhedron 2015, 91, 10-17.

19. S. Thakurta, R. J. Butcher, C. J. Gomez-García, E. Garribba and S . Mitra, Inorg. Chim. Acta 2010, 363, 3981-3986.

20. (a) P. C. H. Mitchell and R. J. P. Williams, J. Chem. Soc., 1960, 1912-1918; (b) R. A. Bailey, S. L. Kozak, T.W. Michelsen and W.N. Mills, Coord. Chem. Rev., 1971, 6, 407-445.

21. A. Sabatini and I. Bertini, Inorg. Chem. 1965, 4, 959-961.

22. U. Singh, M. M. Dar, S. Anayutullah, H. Alam, N. Manzoor, S. Ahmed Al-Thabaiti and A. A. Hashmi, J. Coord. Chem., 2015, 68, 2096-2106.

23. S. Roy, T. Basak, S. Khan, M. G. B. Drew, A. Bauzá, A. Frontera and S. Chattopadhyay, ChemistrySelect 2017, 2, 9336-9343.

24. (a) S.S. Tandon, L.K. Thompson, M.E. Manuel and J.N. Bridson, Inorg. Chem. 1994, 33, 5555-5570; (b) E. Ruiz, J. Cano, S. Alvarez and P. Alemany, J. Am. Chem. Soc. 1998, 120, $11122-11129$.

25. (a) P. Manikandar, R. Muthukumaran, K.R.J. Thomas, B. Varghese, C.V.R. Chandramouli and P.T. Manoharan, Inorg. Chem. 2001, 40, 2378-2389; (b) X.J. Lin, Z. Shen, Y. Song, H.J. Xu, Y.Z. Li and X.Z. You, Inorg. Chim. Acta 2005, 358, 1963-1969. 


\section{End-on cyanate or end-to-end thiocyanate bridged dinuclear}

\section{copper(II) complexes with a tridentate Schiff base blocking ligand:}

\section{Synthesis, structure and magnetic studies}

\section{Samim Khan, Stephen Sproules, Louise S. Natrajan, Klaus Harms, Shouvik Chattopadhyay}

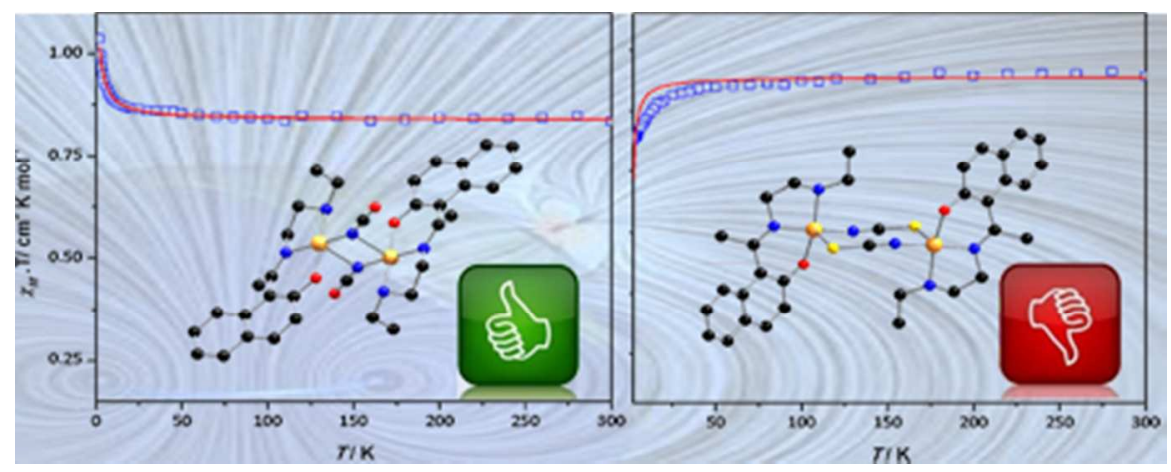

Two new dinuclear Schiff base copper(II) complexes have been synthesized and well characterized by elemental analysis and X-ray crystallography. Ferromagnetic exchange coupling interaction between copper(II) centres is mediated via end-on cyanate bridge in complex 1, whereas antiferromagnetic exchange coupling ids mediated via end-to-end thiocyanate bridge in $\mathbf{2}$. 